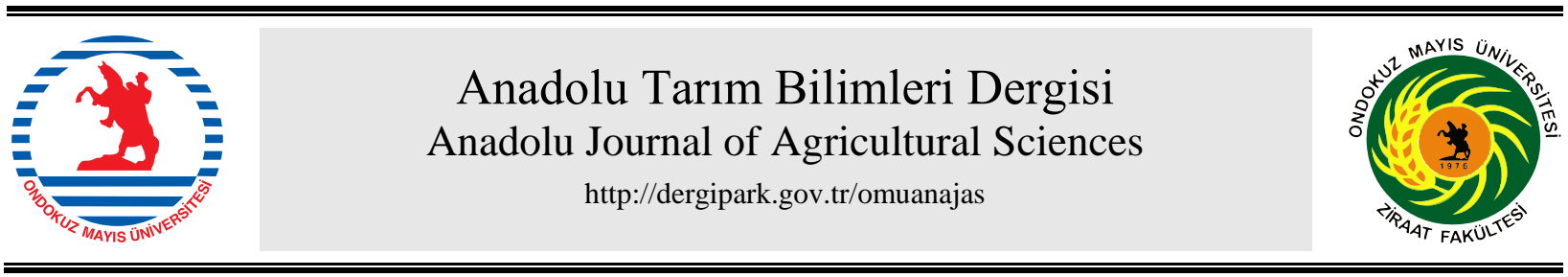

Research

Anadolu Tarım Bilim. Derg./Anadolu J Agr Sci, 34 (2019) ISSN: 1308-8750 (Print) 1308-8769 (Online) doi: $10.7161 /$ omuanajas. 484655

\title{
Leaflet shape analysis separates rose cultivars and estimates leaf area
}

\author{
Mansour Matloobi*, Sepideh Tahmasebi, Faribourz Zare Nahandi, Alireza Motallebi-Azar
}

Department of Horticulture, University of Tabriz, Tabriz, Iran

*Correspondent author: matloobi@tabrizu.ac.ir

Received 18/11/2018 Accepted 24/09/2019

\begin{abstract}
Trying to use tip leaflet of rose plants as a sample to estimate leaf area and to separate rose cultivars, in an experiment we took leaf images from three different stem layers of four garden roses. After preliminary image pre-processing measures, some important leaf geometric features such as leaf and leaflet area, perimeter, circularity and leaflet length and width were measured or calculated. Analysis of variance showed that it would be possible to separate rose cultivars by including only two leaf properties, i.e., tip leaflet angle and leaflet area to leaf area ratio. It was also determined that three leaf layers along the rose stem can be recognized and categorized by implementing just angle of tip leaflet. Leaflet area was agreeably approximated by fitting a simple linear model to the product of leaflet minor and major axes. Further analyses indicated that some leaflet properties such as solidity, perimeter and circularity can be used as significant criteria to distinguish rose cultivars, however other features like leaflet elongation and rectangularity were quite poor and insignificant in this case. In conclusion, it was determined that rose leaflet tip angle not only has the ability of being as a good morphometric marker in separating rose stem leaf layers but also it is capable of identifying different rose cultivars.
\end{abstract}

Keywords:

Image analysis

Leaf morphometric

features

Leaf area

Leaflet shape

Rose

\section{Introduction}

Roses are one of the world's most economically important flowers (Niu and Rodriguez, 2009) which belong to Rosa genus containing about 200 species and more than 20,000 cultivars (Cuizhi and Robertson, 2003; Ritz et al, 2005). There are tremendous variations of growth habit, leaf and flower form, size and color across rose cultivars. As in many species of plants, organ size in rose plants is also influenced by a great number of environmental factors, such as light quality (Maas and Bakx,1995), light intensity (Bredmose,1993), day length (Cookson et al., 2007), water (Demotes Mainard et al.,2013), nitrogen availability (Ashok and Rengasamy,2000), mechanical stimulation (Morel et al.,2012) and genotype (Morel et al.,2009) as well. Leaves are the primary photosynthetic organ in plants with the greatest amount of information which make them worthy for taxonomists in species identification. Moreover, leaves can be easily found and collected almost in most time of the growing season, whereas flowers and fruits are available only for a few weeks during the year (Cerutti at el 2011). This is why the most plant identification tools are based on the leaf morphological information (Wang at el 2003). A leaf can be characterized by its shape, color and texture. The color of a leaf may change by the variation of climatic conditions, season and even by the level of nutrient availability. In addition, most plants have leaves colored in green which makes it appropriate enough for species recognition (Mouine at el 2012).

Each leaf has its own shape and feature that carries significant information (Hossain and Amin, 2010), and varies developmentally and environmentally within a plant (Chitwood et al., 2012a). For these reasons studies on leaf morphology require measurement of multiple parameters from numerous leaves (Chitwood et al., 2012 b). Plants species produce leaves that are normally very diverse in shape and size, providing researchers a great opportunity to identify and distinguish species. Within species and even a single plant, leaf characteristics may differ significantly (Kerstetter, 1998). Leaf shape variability has been investigated using analysis of landmarks and it was emerged that this method might be very accurate in identification of species (Jensen, 1990). Leaf shape is a highly heritable property of leaf morphology. Intrinsic difference in leaf shape can restrict phenotypes in disparate organs. For example, it has been shown in tomato that there is a relationship between leaf shape and sugar accumulation in fruit, this result is consistent with the hypothesis that leaf shape can impact photosynthesis (Chitwood et al., 
2013).

Estimation of leaf area is an essential component in plant taxonomy (Bel and Bryan, 2008) and many types of physiological studies, such as plant growth rate (Leith et al., 1986; Rouphael et al., 2010), transpiration and water requirement determination (Enoch and Hurd, 1979) and photosynthesis (Boote et al., 1986; Spann and Heerema, 2010). In crop culture, production of a minimum leaf area is a prerequisite to reach the optimal yield and proper canopy energy balance (Jonckheere et al., 2004; Antunes et al., 2008; Kandiannan et al., 2009).

Monitoring of leaf morphology could be also very important in some researches, especially those related to the role of environmental and developmental biology (Baret et al., 2004). Before the introduction of digital photography most studies in this area were performed using a few known traditional methods (Marcus, 1990; Jensen, 2003). Measuring leaf area normally involves either direct or indirect method. However, direct (destructive) methods have often been selected as most accurate method by many researchers, yet it usually appears to be much expensive and time consuming (Landis et al., 2002). Indirect methods are nondestructive, fairly rapid and inexpensive (Baret et al., 2004).

Digital images acquired automatically for measuring purposes in plants, are applicable to monitor plant growth (Spalding and Miller, 2013). Leaves are widely used for computer-aided plant classification. Examples of such studies include hierarchical polygon approximation and representation of leaf shape in order to classify the members of Acer family (Im et al.1998), Soybean leaf classification (Oide and Ninomiya., 2000), computer-aided plant species identification (Du et al.,2006), leaf edge shape detection (Huff at el., 2003), determining size and number of leaf teeth (Royer \& Wilf, 2006) and estimating prehistoric climates using fossilized leaves shape (Ellis et al., 2009). In the present study we tried to separate rose cultivars through simple leaf morphometric features and apply linear models to estimate leaf and leaflet area by implementing leaf geometric information.

\section{Materials and Methods}

\subsection{Plant Materials}

The experiment was conducted in the research greenhouse of the University of Tabriz (Tabriz, Iran). The hybrid tea rose cultivars used in the study (Caribia, Full House, Cherry Brandy and Polar Star) were obtained from a commercial rose greenhouse. When selecting the plants there was an attempt to choose the plants at the same developmental stages having uniform growth specifications. Rose plants were transferred to 7 $\mathrm{L}$ plastic pots containing 70\% Coco Peat and 30\% Perlite. They were then grown under the natural photoperiod with the temperatures ranged from $18.0 \pm$ $2^{\circ} \mathrm{C}$ to $28.0 \pm 2{ }^{\circ} \mathrm{C}$ and relative humidity (RH) between
$55 \%$ to $70 \%$. Plants were irrigated and fertilized using a standard nutrient solution to sustain proper plant growth and development. The experiment was started on May 26, 2014 and finished on August 26, 2014.

\subsection{Image samples}

Each matured flowering stem were equally divided into 3 layers. Individual leaves were randomly taken from each layer and then were photographed using below mentioned method.

\subsection{Digital image acquisition}

The images of rose leaves were acquired in RGB color medium using a SLR digital camera (Canon's EOS 550D, Japan). The images were taken by applying the following camera settings: shutter speed: $1 / 125 \mathrm{~s}$, ISO: 200, focal length: $35 \mathrm{~mm}$ and image resolution of 5184 in 3456 pixels. All the images were taken under the natural sun light condition against a white background with a $1 \mathrm{~cm}^{2}$ scale attached to it. Images were saved in JPEG format with 256 grey levels per each color channel. The Image $\mathrm{j}$ software (National Institutes of Health, Bethesda, Maryland, USA; version 1.4, free download form http://imagej.en.softonic.com/) with the latest relevant plugins were used to analyze the images. Image J was well known by many researchers as a reliable and reputable software for performing geometric measurements (Orsini et al., 2010; Warman et al., 2011; Juneau and Tarasoff, 2012; Carins Murphy et al., 2012; Schneider et al., 2012).

\subsection{Image pre-processing}

Before starting main processing stage, images were subjected to some pre -processing operations. In this phase obtained color images were converted into a normalized grayscale equivalent image by transforming them into 8 bit images (Lee and Hongs, 2013). The formula presented in equation 1 was used to convert RGB value of a pixel into its grayscale value. Leaf images were then converted to binary image by thresholding the grays-scale images (Abramoff et al., 2004). The images were then saved in JPEG format. Fig. 1 shows an example of leaf contour extraction.

Gray $=0.2989 * \mathrm{R}+0.5870 * \mathrm{G}+0.1140 * \mathrm{~B}$

Where R, G, B corresponds to the color of the pixel, respectively

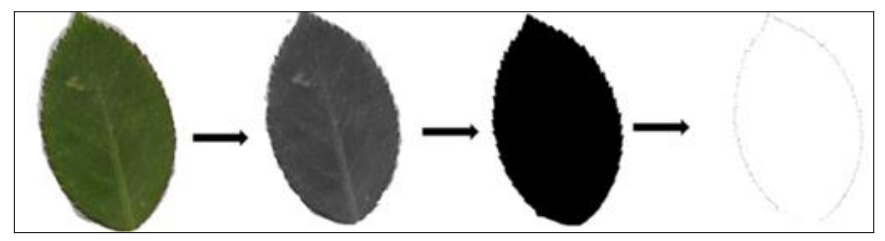

Figure 1. Leaf features extraction 


\subsection{Shape features extraction}

Using imageJ software leaf basic geometric parameters were measured or calculated as follows:

- Major axis length (L): length of the longest line that can be drawn through the leaflet.

- Minor axis length (W): length of the longest line that can be drawn through the leaflet perpendicular to the major axis.

- Area (A): The value of leaflet area was measured by counting the number of pixels of binary image and comparing it with the pixel number of $1 \mathrm{~cm}^{2}$ scale sign.

- Perimeter (P): Perimeter of leaflet which was obtained by measuring leaflet perimeter.

- Elongation: defined as L/W.

- Circularity: This feature is used to describe the difference between a circle and a leaflet. It is defined as $4 \pi \mathrm{A} / \mathrm{P}^{2}$.

- Rectangularity: This feature describes the similarity between a rectangle and a leaf and is defined as LW/A.

- Solidity: defined as $\mathrm{A} / \mathrm{A}_{\mathrm{CA}}$, where $\mathrm{A}$ is the leaflet area and $\mathrm{A}_{\mathrm{CA}}$ is the area of leaflet convex hull.

- Compactness: defined as: sqrt $\left(4 \mathrm{~A} \pi^{-1} \mathrm{~L}^{-1}\right)$.

- Feret diameter: diameter of a circle having the same area of the leaflet.

- Tip leaflet angle: The angle formed in leaflet tip by drawing lines from leaflet tip to the first recognizable teeth on either side of the leaflet.

- LeafletA/LeafA (LLA/LA): ratio of leaf tip leaflet area to corresponding total leaf area

\subsection{Experimental design and statistic}

The experimental design consisted of two factors (cultivar and stem layers) crossed according to split plot design. Main plot (cultivar) was replicated 4 times and randomized based on CRD and hosted 3 equal levels of matured flower stem layers as sub plot. All the recorded data were analyzed using analysis of variance (ANOVA) procedure after being subjected to normality test and undergoing data transformation wherever needed using the Statistical Software Package (MiniTab 17.0).

\section{Result and Discussion}

Table 1 shows the results of ANOVA for measured characteristics. Some leaflet morphometric properties varied across cultivars, however only tip leaflet angle and leaflet/leaf ratio changed significantly among the stem layers.

Table1. Analysis of variance for tip leaflet geometric parameters

\begin{tabular}{|c|c|c|c|c|c|c|c|c|}
\hline SOV & df & Major axis & Minor axis & Area & Perimeter & Circularity & Solidity & $\begin{array}{l}\text { Tip leaflet } \\
\text { angle }\end{array}$ \\
\hline Cultivar & 3 & $0.765 \mathrm{~ns}$ & $1.5^{*}$ & $41.696 \mathrm{~ns}$ & $35.83 * *$ & $253.73 *$ & $7.54 * *$ & $2734.053 * *$ \\
\hline Main Error & 8 & 0.583 & 0.341 & 16.088 & 5.81 & 59.51 & 1.038 & 243.891 \\
\hline Layer & 2 & $0.645 \mathrm{~ns}$ & $0.501 \mathrm{~ns}$ & $15.115 \mathrm{~ns}$ & $12.79 \mathrm{~ns}$ & 5.810 & $\begin{array}{l}1.758 \\
\text { ns }\end{array}$ & $90.411 * *$ \\
\hline Cultivar*Layer & 6 & $0.829 \mathrm{~ns}$ & $0.286 \mathrm{~ns}$ & $17.304 \mathrm{~ns}$ & $14.33 \mathrm{~ns}$ & $58.204 \mathrm{~ns}$ & $\begin{array}{l}1.137 \\
\text { ns }\end{array}$ & $86.007 * *$ \\
\hline Sub Error & 16 & 0.7 & 0.432 & 16.914 & 10.00 & 28.490 & 2.142 & 15.456 \\
\hline SOV & df & Elongation & Rectangularity & Compactness & $\begin{array}{l}\text { Feret } \\
\text { Diam. }\end{array}$ & LeafletA/LeafA & & \\
\hline Cultivar & 3 & $0.118 \mathrm{~ns}$ & $0.028 \mathrm{~ns}$ & $0.088 \mathrm{~ns}$ & $0.247 \mathrm{~ns}$ & $197.42 * *$ & & \\
\hline Main Error & 8 & 0.031 & 0.021 & 0.025 & 0.089 & 8.50 & & \\
\hline Layer & 2 & $0.018 \mathrm{~ns}$ & $0.014 \mathrm{~ns}$ & $0.039 \mathrm{~ns}$ & $0.117 \mathrm{~ns}$ & $130.94 * *$ & & \\
\hline Cultivar*Layer & 6 & $0.024 \mathrm{~ns}$ & $0.015 \mathrm{~ns}$ & $0.037 \mathrm{~ns}$ & $0.125 \mathrm{~ns}$ & $44.06 * *$ & & \\
\hline Sub Error & 16 & 0.027 & 0.005 & 0.027 & 0.108 & 5.960 & & \\
\hline
\end{tabular}

$\mathrm{ns}, *$ and $* *$ denote respectively non-significant, significant at the $5 \%$ and $1 \%$ level

Cultivar 'Full house' indicated the longest leaflet minor axis and the longest leaflet perimeter as well, while it offered the lowest degree of tip leaflet angle when compared with the other cultivars. On the other hand, tip leaflet of cultivar 'Polar star' in spite of showing the highest degree of leaflet angle, accounted for only about $24 \%$ of total leaf area while it shared almost $40 \%$ of total leaf area in 'Carribia'. However, leaflet circularity and solidity were the highest in this cultivar. Tip leaflet angle beside the leaf area participation of tip leaflet significantly differed across the stem layers (Table 2). In this case, top layer showed the widest angle of tip leaflet and accounted for much percentage of total leaf area (Fig2).

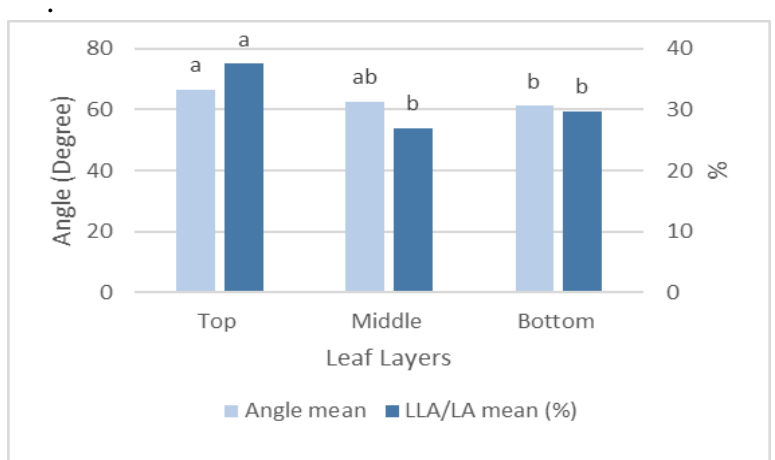

Figure 2. Tip leaflet angle and leaflet area to leaf area ratio variations across three stem layers 
Table 2. Mean comparisons of cultivars' significant characteristics

\begin{tabular}{lcccccc}
\hline Cultivars & $\begin{array}{c}\text { Leaflet minor } \\
\text { axis }(\mathrm{cm})\end{array}$ & $\begin{array}{c}\text { Leaflet perimeter } \\
(\mathrm{cm})\end{array}$ & Circularity & Solidity & Angle (degree) & LLA/LA \\
\hline Carribia & $2.90 \mathrm{~b}$ & $14.51 \mathrm{~b}$ & $53.91 \mathrm{a}$ & $80.15 \mathrm{a}$ & $76.68 \mathrm{a}$ & $0.412 \mathrm{a}$ \\
Cherry Brandy & $3.29 \mathrm{ab}$ & $18.50 \mathrm{ab}$ & $41.09 \mathrm{~b}$ & $78.15 \mathrm{~b}$ & $66.93 \mathrm{~b}$ & $0.335 \mathrm{~b}$ \\
Full House & $3.84 \mathrm{a}$ & $18.95 \mathrm{a}$ & $47.69 \mathrm{ab}$ & $78.34 \mathrm{ab}$ & $38.16 \mathrm{c}$ & $0.278 \mathrm{c}$ \\
Polar Star & $3.09 \mathrm{ab}$ & $17.21 \mathrm{ab}$ & $45.78 \mathrm{~b}$ & $78.53 \mathrm{ab}$ & $72.66 \mathrm{a}$ & $0.235 \mathrm{c}$ \\
\hline
\end{tabular}
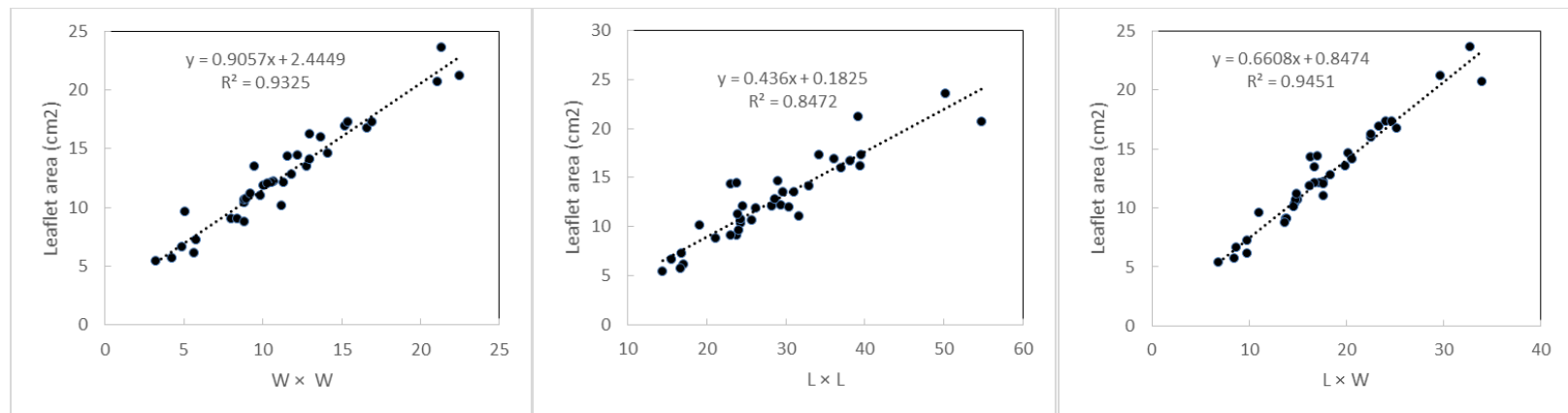

Figure 3. Leaflet area variations by leaflet shape parameters

Linear model appeared to best describe the relationship between the leaflet axis parameters and leaflet area (Fig. 3). When the product of minor and major leaflet axes was used to predict the leaflet area, the highest rate of R2 (coefficient of determination) was obtained. However, this parameter was not calculated with the same magnitude for linear description of the leaf area variations by leaflet area. Comparing different leaf layers an agreeable relationship was found between leaf and leaflet area almost among all layers (Fig. 4)

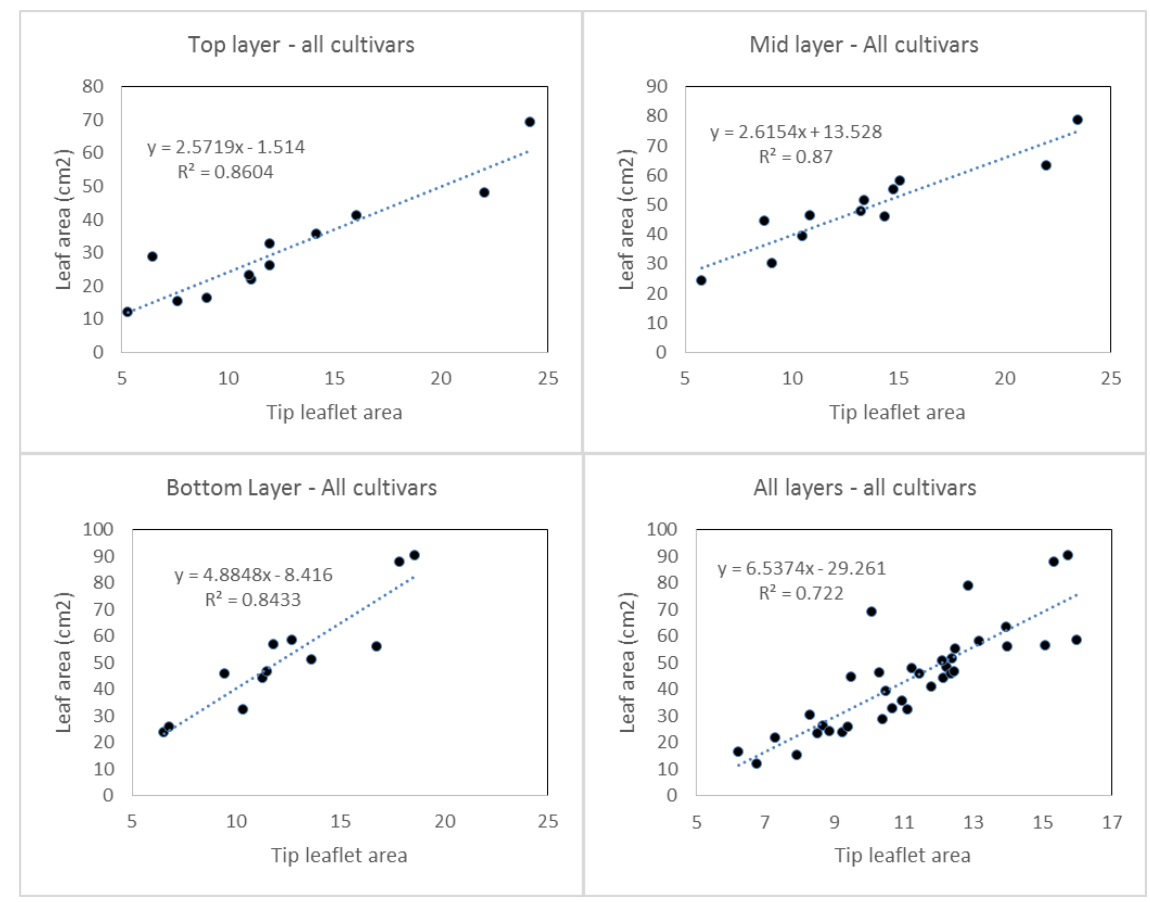

Figure 4. Relationship between leaf are and tip leaflet area in different stem layers

Many methods have already been tried by some authors to classify plant species and varieties (Waldchen and Mader, 2017). One of the simplest and fast responsive methods in separating plant cultivars might be applying leaf geometric properties (Viscosi and Cardini., 2011). In this study several leaflet parameters of four rose cultivars were statistically examined to see possible significant differences among the cultivars. Mean comparison of leaflet properties revealed that it would be possible to separate all the studied rose cultivars by applying only two leaflet parameters, i.e. leaflet angle and LLA/LA ratio. Neural network 
analysis has already been used successfully to identify and separate 10 olive cultivars using leaf morphometric features as input data (Mancuso and Nicese, 1999). Leaf minor axis proved to be a good morphometric marker in rose cultivar identification when compared with the leaf major axis (Rouphael et al., 2010). In muskmelon leaf width was found to be a better fit than the leaf length in estimating leaf area by allometry method (Misle et al.,2012). In another study Eftekhari (Eftekhari, et al, 2011) determined table grape leaf area by developing a simple model implementing variables of leaf width and length. In our study, product of leaf width and leaf length was found to be a very suitable and useful variable in predicting rose leaflet area using a simple linear model. Oner (Oner et al., 2011) introduced a multiregression model to predict corn leaf area using leaf width, length and leaf zone of the plant. In rose plant Rouphael (Rouphael, et al., 2010) found that a linear model having $\mathrm{L} \times \mathrm{W}$ as the independent variable provided the most accurate estimate of rose leaf area. Additionally, according to our results, a relationship was found between leaflet area and total leaf area, although with lower rate of R2 showing that by having only leaflet area one can roughly estimate the total leaf area. Leaf features such as area and size are frequently recorded variables in plant research, as they can be important indicators of variability within and among populations (Aravanopoulos, 2005).

The results of our study in leaf area prediction were consistent with Cristofori et al (2007) who suggested that leaf area in hazelnut and persimmon strongly related to $\mathrm{L} \times \mathrm{W}$. Blanco and Folegatti (2005) predicted leaf area by a linear model $\mathrm{LA}=-4.27+0.88 \mathrm{~L} \times \mathrm{W}$ with high accuracy and only little differences observed between the cultivars and environment. Tsialtas and Maslaris (2008) documented that in sugar beet a model developed based on leaf dimensions [LA $=31.928$ $+0.5083 \mathrm{~L} \times \mathrm{W}]$ satisfactorily predicted LA better than when the leaf width or length was solely used. Similarly, Lu et al (2004) proposed that the simple and linear relationships between leaf area and leaf dimensions (length and width) might be useful for nondestructive estimation of plants leaf area.

Gao (Gao et al., 2012) studied the effect of genotype and environment on rose leaf area estimation. They found that for proper estimation of leaf area across different environments and genotypes, measuring only leaf length isn't enough until other variables like leaf width included. Developing a dynamic model for re-constructing data of shoot leaf area increment in pot chrysanthemum, Larsen and Nothnagl (Larsen and Nothnagel, 2008) reported that despite of being an allometric relationship between leaf length and leaf area in the cultivar studied, more researches needed to expand the model to other chrysanthemum cultivars. Given that leaf morphological properties usually influenced by growth stage and environmental factors, adding other determinant and stable physical parameters with proper combinations to model inputs may lead us to much more accurate leaf area estimations.

\section{Conclusion}

In this study the leaf area of some cut rose cultivars were modeled by using simple nondestructive allometric relationships between tip leaflet and leaf dimensions. Furthermore, it was found that leaflet morphometric features could be used to identify rose cultivars almost most of the year whenever leaves are available. This is important particularly in nurserys where mother plants are usually out of flower due to continuous stem harvesting which therefore making cultivar identification rather difficult for nursery-man and even plant buyers prior to flowering time of plants. In addition to growers, using the method reported in this study, researchers would also acquire a useful tool to determine important leaf morphometry characteristics of rose plants in their related studies. This study on one hand gave significance of different combinations of rose leaf dimensions in estimating leaf area and on the other hand, confirmed the ability of leaf shape analysis via image processing technique in identification of rose cultivars by including tip leaflet angle of rose leaves.

\section{References}

Abramoff, M.D., Magalhaes, P.J., Ram, S.J., 2004. Image processing with imageJ. Biophotonics International. 11, 36-42.

Ashok, A.D., Rengasamy, P., 2000. Effect of nitrogen fertigation at different levels and sources on the growth of cut rose cv. first red under greenhouse conditions. South Indian Hortic. 48,139-141.

Antunes W.C., Pompelli, M.F., Carretero, D.M., DaMatta, F.M., 2008. Allometric models for nondestructive leaf area estimation in coffee (Coffea arabica and Coffea canephora). Annals of Applied Biology. 153,33-40.

Aravanopoulos, F.A., 2005. Phenotypic variation and population relationships of chestnut (Castanea sativa) in greece, Revealed by Multivariate Analysis of Leaf Morphometrics. Acta Hortic. 693, 233-240.

Baret, F., Coppin, P., Fleck, S., Jonckheere, I., Muys, B., Nackaerts, K., Weiss, M., 2004. Review of methods for in situ leaf area index determination 
Part I. Theories, sensors and hemispherical photography. Agr Forest Meteorol. 121,19-35.

Bell, A., Bryan, A., 2008. Plant Form: An illustrated guide to flowering plant morphology. London: Timber Press. 432.

Blanco, F.F., Folegatti, M.V., 2005. Estimation of leaf area for greenhouse cucumber by linear measurements under salinity and grafting. Scientia Agricola, 62, 305-309.

Boote, K.J., Jones, J.W., Hoogenboom, G., 1986. Research and management application of the PNUTGRO crop growth model. Proc. Am. Peanut Res. Edu. Soc. 20, 57.

Bredmose, N, Hansen, J., Nielsen, J., 2001. Topophysic influences on rose bud and shoot growth and flower development are determined by endogenous axillary bud factors, in III International Symposium on Rose Research and Cultivation, eds N. Zieslin and H.Agbaria (Herzliya: International Society Horticultural Science).177-183.

Carins Murphy, M.R., Jordan, G.J., Brodribb, T.J., 2012. Differential leaf expansion can enable hydraulic acclimation to sun and shade. Plant, Cell and Environment, 35,1407-1418.

Cerutti, G.L., Tougne, A., Vacavant, C, D., 2011. A parametric active polygon for leaf segmentation and shape estimation. In International Symposium on Visual Computing (ISVC). 202-213.

Chitwood, D.H., Headland, L.R., Filiault, D.L., Kumar, R., Jimenez Gomez, J.M., Schrager, A.V., 2012. Native environment modulates leaf size and response to simulated foliar shade across wild tomato species. PLoS ONE. 7:e29570.

Chitwood, D.H., Headland, L.R., Kumar, R., Peng, J., Maloof, J.N., Sinha, N.R., 2012 b. The developmental trajectory of leaflet morphology in wild tomato species. Plant Physiol. 158:1230-1240.

Chitwood, D.H., Kumar, R., Headland, L.R., Ranjan, A., Covington, M.F., Ichihashi, Y., Fulop, D., Jimnez-Gomez, J.M., Peng, J., Maloof, J.N., 2013. A quantitative genetic basis for leaf morphology in a set of precisely defined tomato introgression lines. Plant Cell. 25,2465-2481.

Cristofori, V., Rouphael, Y., Mendoza-de Gyves, E., Bignami, C.. 2007. A simple model for estimating leaf area of hazelnut from linear measurements. Scientia Horticulturae, 113,221-225.

Cookson, S.J., Chenu, K., Granier, C., 2007. length affects the dynamics of leaf expansion and cellular development in Arabidopsis thaliana partially through floral transition timing. Ann. Bot. 99,703711.

Cuizhi, G., Robertson, K.R., 2003. Rosa Linnaeus, Sp. Flora of China. 9,339-381.

Demotes, M.S., Huche-Thelier, L., Morel P, Boumaza, R., Guerin, V., Sakr, S., 2013.Temporary water restriction or light intensity limitation promotes branching in rosebush. Sci. Hortic. 150,432-440.
Du, J., Huang, D., Wang, X., Gu, X., 2006. Computeraided plant species identification (CAPSI) based on leaf shape matching technique. Transactions of the Institute of Measurement and Control. 28,275-284.

Eftekhari, M., BKamkar, B., Alizadeh, M., 2011. Prediction of leaf area in some Iranian table grape (Vitis vinifera L.) cuttings by a non-destructive and simple method. Science Research Reporter.1,115121.

Ellis, B., Daly, D.C., Hickey, L.J., Johnson, K.R., Mitchell, J.D., Wilf, P., 2009. Manual of leaf architecture. Cornell University Press, Ithaca, New York, USA.

Enoch, H.Z., Hurd, R.G., 1979. The effect of elevated $\mathrm{CO} 2$ concatenation in the atmosphere on plant transpiration and water use efficiency: A study with potted carnation plants. Int. J. Biometer. 23,343351.

Gao, M., Heijden, G. W. A. M. Van Der, Vos, J., Eveleens, B. A., Marcelis, L. F. M., 2012. Estimation of leaf area for large scale phenotyping and modeling of rose genotypes. Scientia Horticulturae, 138: 227-234.

Hossain, J., Amin, M.A., 2010. Leaf shape identification based plant biometrics. Proceedings of 13th International Conference on Computer and Information Technology, Dec. 23-25, IEEE Xplore Press, Dhaka, Bangladesh. 458-463.

Huff, P.M., Wilf, P., Azumar, E.J., 2003. Digital future for paleoclimate estimation from fossil leaves? Preliminary results Palaios. 18: 266-274.

Im, C., Nishida H., Kunii, T.L., 1998. Recognizing plant species by leaf shapes - a case study of the Acer family. Proc. Pattern Recog. 2 ,1171-1173.

Jensen, R.J., 2003. The conundrum of morphometrics. Taxon. 52,663-671.

Jensen, R.J., 1990. Detecting shape variation in oak leaf morphology: a comparison of rotational-fit methods. Am J Bot .77,1279-1293.

Jonckheere, I., Fleck, S., Nackaerts, K., Muys, B., Coppin, P., Weiss, M., Baret, F., 2004. Review of methods for in situ leaf area index determination. I: Theories, sensors and hemispherical photography. Agric. For. Meteorol. 121, 19-35.

Juneau, K.J., Tarasoff, C.S., 2012. Leaf area and water content changes after permanent and temporary storage. PLoS ONE 7: e42604.

Kandiannan, K., Parthasarathy, U., Krishnamurthy. K.S., Thankamani, C.K., Srinivasan, V., 2009. Modelling individual leaf area of ginger (Zingiber officinale Roscoe) using leaf length and width. Scientia Horticulturae. 120,532-537.

Kerstetter, R.A., Poethig, R.S., 1998. The specification of leaf identity during shoot development. Annu. Rev. Cell Dev. Biol. 14,373-398.

Larsen, R. U., Nothnagl, M. 2008. Re-constructing data of leaf area increment in the greenhouse pot chrysanthemum cultivar ' Lompoc ,' Scientia Horticulturae. 117: 63-68. 
Landis, D.A., Isaacs, R., Neal, M.E., 2002. An Inexpensive, Accurate method for measuring leaf area and defoliation through digital image analysis. J Econ Entomol. 95,1190-1194.

Leith, J.H., Reynolds, J.P., Rogers, H.H., 1986. Estimation of leaf area of soybeans grown under elevated carbon dioxide levels. Field Crops Res. 13,193-203.

Lee, K.B., Hong, K.S., 2013. An implementation of leaf recognition system using leaf vein and shape. International Journal of Bio-Science and BioTechnology. 57-66.

Lu, H., Lu, Y., Wei, M.L., Chan, L.F., 2004. Comparison of different models for nondestructive leaf area estimation in taro. Agronomy Journal. 96, 448-453.

Maas, F.M., Bakx, E.J., 1995. light on growth and flowering of Rosa hybrida 'Mercedes'. J. Am. Soc. Sci. 120,571-576.

Marcus, L.F., Rohlf. F.J., Bookstein, F.L., 1990. Traditional morphometrics. In Proceedings of the Michigan morphometrics workshop. Ann Arbor: University of Michigan press .227-236.

Misle, E., Kahlaoui, B., Hachicha, M., Alvarado, P., 2013. Leaf area estimation in muskmelon by allometry, Photosynthetica, 51,613-620.

Morel, P., Crespel, L., Galopin, G., Moulia, B., 2012. Effect of mechanical stimulation on the growth and branching of garden rose. Sci. Hortic. 135,59-64.

Morel, P., Galopin, G., Dones, N., 2009. Using architectural analysis to compare the shape of two hybrid tea rose genotypes. Sci. Hortic. 120,391-398.

Mouine, S., Yahiaoui, I., Yahiaoui, A., 2012. Advanced shape context for plant species identification using leaf image retrieval. "ICMR '12 - 2nd ACM International Conference on Multimedia Retrieval.

Niu, G., Rodriguez, D.S., 2009. Growth and Physiological Responses of Four Rose Rootstocks to Drought Stress. Journal of the American Society for Horticultural Science. 134,202-209.

Oide, M., Ninomiya, S., 2000. Discrimination of soybean leaflet shape by neural networks with image input. Comput. Electron. Agric. 29:59-72.

Oner, F., Odabas, M.S., Sezer, I., Odabas, F., 2011. Leaf area prediction for corn (Zea mays L.) cultivars with multiregression analysis. Photosynthetica, 49,637-640.

OrsiniI, F., D’urzo, M.P., Inan, G., Serra, S., OH, D.H., Mickelbart, M.V., Consiglio, F., 2010. A comparative study of salt tolerance parameters in 11 wild relatives of Arabidopsis thaliana. Journal of Experimental Botany. 61,3787 -3798.

Ritz, C.M., Schmuths, H., Wissemann, V., 2005. Evolution by reticulation: European dogroses originated by multiple hybridization across the genus Rosa. J. Heredity. 96,4-14.

Rouphael, Y., Cardarelli, M., Ajouz, N., Marucci, A., Colla, G., 2010. Estimation of leaf number of eggplant using thermal time model. Journal of Food Agriculture and Environment. 8,847-850.

Rouphael, Y., Mouneimne, A.H., Ismail, A., Mendozade Gyves, E., Rivera, C.M., 2010. Modeling individual leaf area of rose (Rosa hybrida L.) based on leaf length and width measurement. Photosynthetica. 48,9-15.

Royer, D.L., Wilf, P., 2006. Why do toothed leaves correlate with cold climates? Gas exchange at leaf margins provides new insights into a classic paleotemperature proxy. International Journal of Plant Sciences. 167,11-18.

Schneider, C.A., Rasband, W.S., Eliceiri, K.W., 2012. NIH Image to ImageJ: 25 years of image analysis. Nature Methods. 9,671- 675.

Spalding, E.P., Miller, N.D., 2013. Image analysis is driving a renaissance in growth measurement, Curr. Opin. Plant Biol. 16,100-104.

Spann, T.M., Heerema, R.J., 2010. A simple method for nondestructive estimation of total shoot leaf area in tree fruit crops. Scientia Horticulturae. 125,528-533.

Tsialtas, J.T., Maslaris, N., 2008. Nitrogen fertilization affects on leaf morphology and evaluation of leaf area and LAI prediction models in sugar beet. Photosynthetica. 46, 346-350.

Viscosi, V., Cardini, A., 2011. Leaf Morphology, Taxonomy and Geometric Morphometrics: A Simplified Protocol for Beginners. PLoS ONE 6(10): 25630.

Waldchen, J., Mader, P., 2017. Plant Species Identification Using Computer Vision Techniques: A Systematic Literature Review. Archives of Computational Methods in Engineering. 1-37.

Wang, Z., Feng, D., 2003. Shape based leaf image retrieval. IEE Proceedings on Vision, Image and Processing. 150:34- 43.

Warman, L., Moles, A.T., Edwards, W., 2011. Not so simple after all: Searching for ecological advantages of compound leaves. Oikos. 120,813 821. 